\title{
Analysis of human behavioral attributes in improving disaster evacuation strategy of mount merapi
}

\author{
Anna Maria Sri Asih ${ }^{1}{ }^{*}$, Ekky Novia Rubbyarta ${ }^{1}$ and Bertha Maya Sopha ${ }^{1}$ \\ ${ }^{1}$ Industrial Engineering Programme, Department of Mechanical and Industrial Engineering, \\ Universitas Gadjah Mada, 55281 Yogyakarta, Indonesia
}

\begin{abstract}
Mount Merapi is one of the active volcanoes in Indonesia. Physical conditions of the Merapi environment which is suitable for farming and tourism attract people to stay in the area although it tends to be more prone to be affected when the eruption disaster occurs. Different public perceptions of disasters when such events occur can influence their behavior and hence community decision-making during evacuation process. Thus, evaluation of the evacuation planning based on population behavior is important to be considered. This study aims to determine attributes that influence the behavior of the people around Mount Merapi during evacuation phase and the relationship between those attributes in order to improve the evacuation strategy. Literature review, survey and interview were conducted to obtain the attributes influencing the behavioral attributes, while Damster-Shafer and Bayesian Network were used to evaluate correlation among attributes. The results indicate that experience of disaster training has a strong correlation to evacuation behavior, followed by trust to community leader and perception of danger. Those three attributes are then considered in the improvement of evacuation strategy.
\end{abstract}

\section{Introduction}

Mount Merapi is one of the active volcanoes in the administrative area of Central Java Province and Yogyakarta Special Province, Indonesia and known as one of the most active volcanoes in Indonesia. The southern slopes are in Sleman district administration of Yogyakarta Special province, and the rest are in Central Java Province, which are Magelang regency on the west side, Boyolali regency on the north and east side, and Klaten regency on the southeast side. Those areas are prone to be affected by eruption of Mount Merapi. According to [1], spatially located populations in vulnerable areas may be

\footnotetext{
* Corresponding author: amsriasih@ugm.ac.id
} 
at higher risk for the impact of the disaster. Thus, evacuation planning is important in order to minimize the number of casualties in those areas..

[1] also stated that the physical condition of the Merapi environment, which is suitable for farming and tourism could attracts the community to remain stay in the area although it tends to be more prone affected when the eruption occurs. It has been identified that there are many people who choose to remain the hazardous area despite experiencing several eruptions [2]. The large-scale onslaught on the eruption of Mount Merapi in 2010 caused a challenge in the evacuation process and resulted in high numbers with nearly 400,000 internally displaced persons [2]. The results of the study indicate that the cause of the high casualties is due to the unpreparedness of the community to evacuate, many of the victims found dead in front of their homes with bags full of clothing or near their owned vehicles.

Evaluation of the evacuation planning based on population behavior needs to consider those experiences to ensure that it can be operated appropriately. But what must be kept in mind is the fact that the society to be saved consists of thousands of people with different decision-making behavior during evacuations. Such behavior needs to be recognized and understood in order to conduct an

analysis that can generate strategies for subsequent effective evacuation and minimize casualties. This

study aims to evaluate the attributes that influence the people behavior in making evacuation decision in Mount Merapi disaster and how those attributes can be used to improve the current evacuation strategies. Literature review, field survey and expert judgement were conducted to obtain the attributes that influence the behavior of the community during disaster evacuation process and their correlation values. The information gained from surveys and expert judgement are then described as conceptual models using a Bayesian Network. It is expected that the results can provide a strategy for better evacuation process.

\section{Literature Review}

Differences in human decision making during disaster evacuation area influenced by information obtained on the development of disaster-related information prior to disaster. [3] assessed the impact of the frequency of information, the type of information, and the accuracy of the warnings given to the evacuation response. If a disaster event is an unexpected event, such as tornado, when the level of emergency preparation is low, then most people tend to resume normal activity when first warned about a future disaster, as if they were in doubt and did not believe the source of the warning came from the authorities. If the appearance of a warning message is unclear, then the tendency to distrust the warning will increase. Their interview on the disaster victims indicated that one of the reasons they did not immediately evacuate and chose to stay in place was because there was no order to evacuate. The results of this study also show that $60 \%$ of disaster victims will evacuate after hearing orders to evacuate. In addition to evacuation command information, other things that affect the evacuation rate are family. Evacuation is almost always happening to a family rather than to individuals. The existence of children is the key determinant. Those with children at home tend to be more likely to evacuate than those who do not have children at home. In addition to children, elderly people are also likely to evacuate because of their physical conditions.

According to [4] there are three types of behavior in following the evacuation orders from the local government. The first is the people who stayed in refugee camps. They are 
mostly are women, children, and parents. Second, about one-fifth of the male population lives in the village of origin to prevent robbers. The third is the people who do not have the money savings choose to stay at the evacuation post at night and return to the village during the day. [5] has conducted research involving experts in the field of Merapi disaster in 2010 to find attributes of differentiating community behavior when making decisions for evacuation and characterize the behavior of the community. In this study, nine attributes were found that represented the distinctive attributes of community behavior around Merapi during evacuation, i.e. vulnerable groups, eruption experiences, livestock ownership, valuable possessions, training experience, trust on cultural leader, traditional belief, perceptions of danger, and social concern. Those nine attributes, together with field survey and expert judgement will then be used by the author to be the basis of this research in order to evaluate the correlation among attributes and how to use in improving current evacuation strategy.

\section{Methodology}

The subject of this study consists of people who live in three villages in the sub-district of Cangkringan and several experts (i.e. the local government officers and professionals who were involved in the disaster management in Yogyakarta). The selected villages are based on the severity of damage during the eruption of Mount Merapi 2010, namely Kepuharjo, Glagaharjo and Umbulharjo villages. Of the 12,310 residents in the three villages, 99 people were taken as the sample for data collection by using Slovin's formula, with a $95 \%$ confidence level, $50 \%$ variability $(\mathrm{p}=0,5)$, and a precision level of $\pm 10 \%$.

The research process consists of several stages:

1. acquisition of knowledge from the literature review on the attributes that influence the behavior of evacuation decision of Merapi 2010 disaster.

2. validation of attributes derived from literature review through seven experts consisting of government officials from the three villages studied, as well as professionals involved in the evacuation process.

3. interview to experts involved in the evacuation process of Merapi disaster 2010 to get the relationship between evacuation behavior attributes. Dempster-Shafer method [6] is used to combine the opinion differences.

4. survey to the communities in the three villages affected by the Merapi disaster in 2010 to be used in analyzing the conditional probability value between attributes by using Bayesian Network. Recommendation of evacuation strategy, focusing on the attributes that have significant contributions on the evacuation process.

\section{Results and discussions}

\subsection{Attributes that influence evacuation behavior}

From the research of [5], there are nine attributes affecting people's behavior when evacuating based on the eruption of Merapi 2010, which are vulnerability, previous disaster experience, ownership of livestock, ownership of valuables, perception of danger, evacuation training, trust on cultural leaders, traditional belief, and social concern. In this study, the ownership of livestock and valuable goods is summarized into one attribute, namely the ownership of livestock/valuables because they have the same behavioral plot of behavior. The validation result with the expert related to the eight attributes shows the 
corresponding result. Thus, the process of surveys and interviews in the next stage are carried out based on these eight attributes.

\subsection{Relationship analysis between attributes}

Expert interviews are conducted to get information about the magnitude of the correlation between attributes. As the opinions are different between experts, it is necessary to generate dominant value to represent the relationships by using Dempster-Shafer theory. The results are presented in Table 1 . There are three possible relationships, which are attribute 1 affects attribute $2(\mathrm{fl} \rightarrow \mathrm{f} 2)$, attribute 2 affects attribute $1(\mathrm{f} 1 \leftarrow \mathrm{f} 2)$, and no relationship between attribute 1 and attribute 2 (f1 $\uparrow$ f2).

Table 1. Results of integrating different opinion between experts

\begin{tabular}{|c|l|c|c|c|}
\hline attribute 1 (f1) & \multicolumn{1}{|c|}{ attribute 2 (f2) } & $\mathbf{f 1 ~} \rightarrow \mathbf{f 2}$ & $\mathbf{f 1} \leftarrow \mathbf{f 2}$ & $\mathbf{f 1} \uparrow \mathbf{f 2}$ \\
\hline \multirow{5}{*}{ Vulnerable groups } & Perception of danger & $\bullet$ & & \\
\hline & Previous disaster experience & & & $\bullet$ \\
\hline & Evacuation training & $\bullet$ & & \\
\hline & Ownership of livestock/valuables & & & $\bullet$ \\
\hline & Trust on community leaders & & & $\bullet$ \\
\hline & Traditional belief & $\bullet$ & & \\
\hline & Social concern & & & $\bullet$ \\
\hline \multirow{5}{*}{ Perception of danger } & Previous disaster experience & & $\bullet$ & \\
\hline & Evacuation training & & $\bullet$ & \\
\hline & Ownership of livestock/valuables & & $\bullet$ & \\
\hline & Trust on community leaders & & $\bullet$ & \\
\hline & Traditional belief & & $\bullet$ & \\
\hline
\end{tabular}




\begin{tabular}{|c|c|c|c|c|}
\hline attribute 1 (f1) & attribute 2 (f2) & $\mathbf{f 1} \rightarrow \mathbf{f 2}$ & f1 $\leftarrow \mathbf{f 2}$ & f1 $\uparrow \mathbf{f 2}$ \\
\hline & Social concern & & & - \\
\hline \multirow{5}{*}{$\begin{array}{l}\text { Previous disaster } \\
\text { experience }\end{array}$} & Evacuation training & - & & \\
\hline & Ownership of livestock/valuables & & & $\bullet$ \\
\hline & Trust on community leaders & - & & \\
\hline & Traditional belief & $\bullet$ & & \\
\hline & Social concern & $\bullet$ & & \\
\hline \multirow{4}{*}{ Evacuation training } & Ownership of livestock/valuables & & $\bullet$ & \\
\hline & Trust on community leaders & $\bullet$ & & \\
\hline & Traditional belief & $\bullet$ & & \\
\hline & Social concern & $\bullet$ & & \\
\hline \multirow{3}{*}{$\begin{array}{c}\text { Ownership of } \\
\text { livestock/valuables }\end{array}$} & Trust on community leaders & & & $\bullet$ \\
\hline & Traditional belief & & & $\bullet$ \\
\hline & Social concern & $\bullet$ & & \\
\hline \multirow{2}{*}{ Trust on cultural leaders } & Traditional belief & $\bullet$ & & \\
\hline & Social concern & $\bullet$ & & \\
\hline Traditional belief & Social concern & & & - \\
\hline
\end{tabular}

The Bayesian Network graph consists the eight attributes that influence the behavior of the Merapi community during evacuation and one node representing the target. The arrows are directed to illustrate the relationship between the attributes that have been obtained from the processing using the Dempster-Shafer theory to obtain a Bayesian Network graph which illustrates the relationship between the eight attributes. Figure 1 shows that most of the respondents are not vulnerable groups and have experienced previous Merapi eruption in 2010. In addition, half of the respondents stated that they often followed the evacuation training, while the rest were classified as rare or occasionally attended training activities. The results of the questionnaire also stated that some of the respondents had livestock or other local resources. In addition, most of the respondents did not really believe in cultural leaders and claimed more trust in the government, but in fact, still a lot of people believed in traditional things which marks the occurrence of eruptions. Most respondents also have a high social concern to prioritize the safety of others during evacuation. Residents were selected randomly and resulted in $44.7 \%$ of respondents having good evacuation behavior.

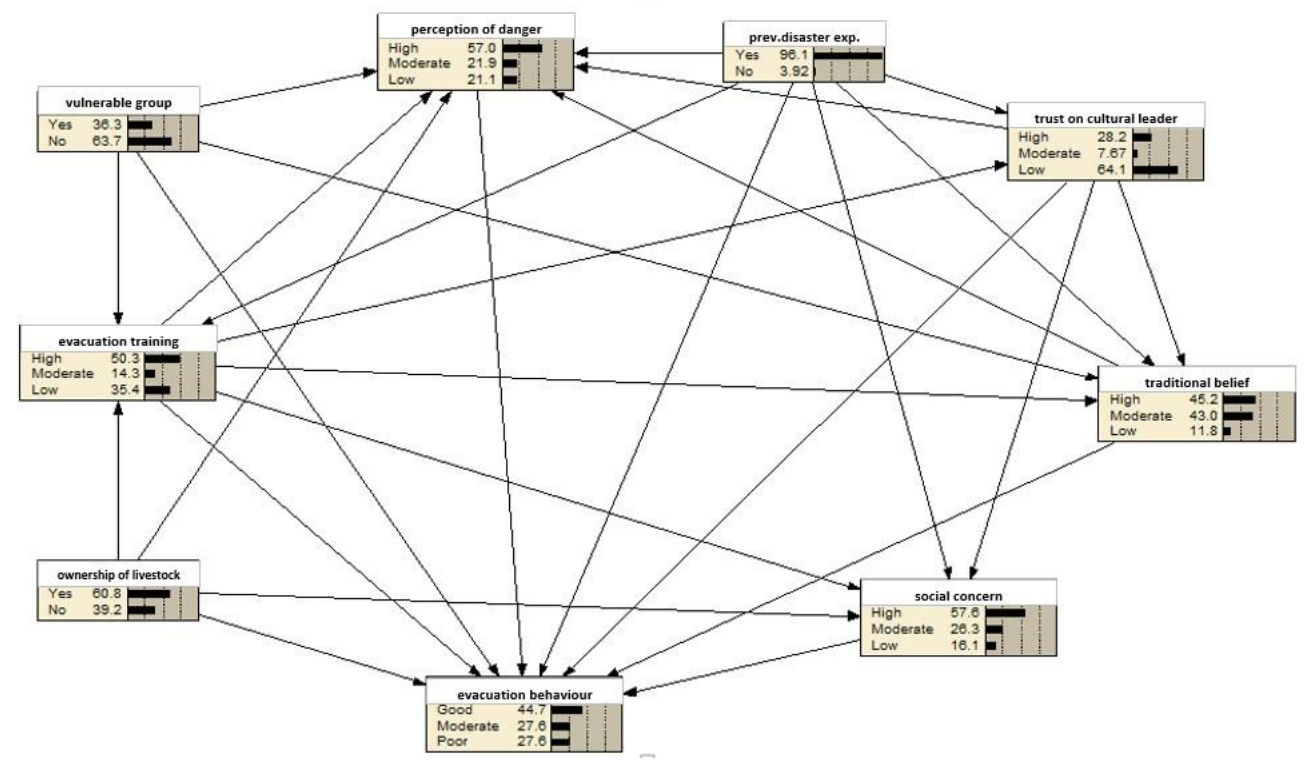

Figure 1. Bayesian network of attributes that influence evacuation behavior 
The mutual information (MI) in Table 2 shows that training experience, traditional belief, and perceptions are the three attributes that have the highest impact on evacuation behavior. The greater the value of mutual information then it indicates a substantial reduction of uncertainty, on the contrary, if mutual information is low then it can be said to provide only a small reduction in the uncertainty of the target node (evacuation behavior).

Table 2. Mutual Information of the attributes

\begin{tabular}{lc}
\hline \multicolumn{1}{c}{ Attributes } & Mutual info \\
\hline Evacuation training & 0,01770 \\
Trust on community leaders & 0,00396 \\
Perception of danger & 0,00253 \\
Traditional belief & 0,00237 \\
Social concern & 0,00187 \\
Ownership of livestock/valuables & 0,00176 \\
\hline
\end{tabular}

\subsection{Improvement Strategy}

Based on the results, the three most influencing attributes in evacuation behavior are evacuation training experience, trust on community leaders, and community perception toward danger. Evaluation of the existing strategy and improvements with respect to the previous analysis are:

a. Evacuation training

Existing condition: the current capacity building of communities for disaster mitigation has not been effectively accommodated. This is supported by the fact that the participants are only representatives of the community who are usually village officials. Thus, it does not make the whole community aware of or even never follow government directive activities aimed at disaster mitigation.

Improvement: Implementation of evacuation training activities could be sinserted into routine activities of hamlet organizations or groups of livestock, and so on. Such a strategy is carried out in order to reach all levels of rural communities around Mount Merapi to gain appropriate knowledge and training on disaster mitigation.

b. Trust on community leaders

Existing condition: a society that believes in a certain character or cultural leader will cause a sizable likelihood of a loss of life if the decision of that person is against the government. Therefore, it is necessary to reduce the level of such kind of trust.

Improvement: Reducing belief in certain cultural leader so that the public trust to the government or disaster management agency that delivers more accurate information increases, could be accomplished by improving the socialization in evacuation training. The conceptual model have shown that the training experience is inversely proportional to the trust on cultural leader, thus the better the community's knowledge about disaster mitigation is expected to lead more people to prioritize information from reliable sources.

c. Perception of danger

Existing condition: people often return to the village or their original residence during the evacuation process. Common cause why the community often returns to the home or neighborhood is to keep the property or valuables owned.

Improvement: the community's habit of preserving the original environment to protect all kinds of investments can be minimized by involving the national arm forces or volunteers from disaster management agencies who have been provided with sufficient knowledge and training to ensure that their valuable resources are safe. 


\section{Conclusion}

Community behavior in making evacuation decisions when disaster occurs is essential in evaluating disaster management strategies to minimize casualties. Eight attributes have been identified and validated as factors that influence evacuation behavior. Using Bayesian Network, evacuation training, trust in leaders and perceptions of danger are the three highest attributes that contribute to community behavior in evacuation. Evacuation training that involves all communities, the proximity of the government to the community, and the role of the government in helping to reduce community concerns about losing property are proposed improvements to existing evacuation strategies.

\section{References}

1. Jumadi, S. Carver, D. Quincey. Procedia Soc Behav Sci. 227, 402-409 (2016)

2. E.T.W. Mei, F. Lavigne, A. Picquout, E. de Bélizal, D. Brunstein, D. Grancher, J. Sartohadi, N. Cholik, C. Vidal. J Volcanol Geotherm Res. 261, 348-365 (2013)

3. H.W. Fischer, G.F. Stine, B.L. Stoker, M.L. Trowbridge, E.M. Drain. Disaster Prev Manag. 4, 4, 30-36 (1995)

4. F. Lavigne, B. de Coster, N. Juvin, F. Flohic, J.C. Gaillard, P. Texier, J. Morin, J. Sartohadi. J Volcanol Geotherm Res. 172, 273-287 (2008)

5. B.M. Sopha, A.M.S. Asih, D.G. Ilmia, H.A. Yuniarto. International Conference of Industrial Engineering and Engineering Management (IEEM), 10-13 December 2017, Singapore

6. I. Mohammadfam, F. Ghasemi, O. Kalatpour, A. Moghimbeigi. Appl Ergon. 58, 35-47 (2017) 